OPEN ACCESS

Edited by:

John J. Foxe,

Albert Einstein College of Medicine,

USA

Reviewed by:

David Eugene Vance,

University of Alabama at Birmingham,

USA

Kathryn Anastos,

Albert Einstein College of Medicine,

USA

*Correspondence:

Silvia Riva,

Department of Health Sciences, Università degli Studi di Milano, Via A.

Di Rudiní 8, Milan 20143, Italy silvia.riva1@unimi.it

Received: 20 November 2014 Accepted: 16 May 2015 Published: 02 June 2015

Citation:

Riva S, Cutica I, Krampe C,

Reinecke LF, Russell-Edu W,

Santoro C, Rocino A, Santagostino E, Rusconi V and Pravettoni G (2015)

A cohort pilot study on HIV-associated neuropsychological impairments in hemophilia patients.

Front. Hum. Neurosci. 9:313. doi: 10.3389/fnhum.2015.00313

\section{A cohort pilot study on HIV-associated neuropsychological impairments in hemophilia patients}

\author{
Silvia Riva ${ }^{1 *}$, Ilaria Cutica ${ }^{1}$, Caspar Krampe ${ }^{1}$, Laura F. Reinecke ${ }^{1}$, William Russell-Edu ${ }^{2}$, \\ Cristina Santoro ${ }^{3}$, Angiola Rocino ${ }^{4}$, Elena Santagostino ${ }^{5}$, Vega Rusconi ${ }^{5}$ and \\ Gabriella Pravettoni ${ }^{1,2}$
}

\begin{abstract}
${ }^{1}$ Department of Health Sciences, University of Milan, Milan, Italy, ${ }^{2}$ European Institute of Oncology (IEO), Milan, Italy, ${ }^{3}$ Haemophilia and Thrombosis Centre, Umberto I Hospital, Rome, Italy, ${ }^{4}$ Haemophilia and Thrombosis Centre, S. Giovanni Bosco Hospital, Naples, Italy, ${ }^{5}$ ABB Haemophilia and Thrombosis Centre, IRCCS Ca'Granda, Milan, Italy
\end{abstract}

Despite advances in the management of HIV infection with the introduction of combination antiretroviral therapy, it is well known that HIV can directly infect the central nervous system and, as a result of such infection, neuropsychological impairments can be manifested. In this study, we tried to determine whether seropositivity was associated with a poor neuropsychological performance in patients with hemophilia and HIV. Such a cohort of patients is very often underrepresented and understudied in the HIV literature. To amend such a gap, we carried out an extensive neuropsychological evaluation on these patients, and compared their performance with that of a group of seronegative hemophilia patients. The results revealed that HIV infection in HIV-seropositive $(\mathrm{HIV}+)$ hemophilia patients was associated with deficits in attention, short-term memory, abstraction, and visual recognition. Such results are still preliminary and explorative due to the small cohort of patients enrolled. However, the results do seem to have some important implications for day-to-day functioning, as the level of impairment detected may cause difficulties in completing common everyday tasks such as maintaining adherence to complex medication regimens or maintaining social life activities. Continued research into the mechanisms related to HIV and neurocognitive dysfunction may provide targets for interventions that could have meaningful consequences in the real world for HIV hemophilia patients.

Keywords: hemophilia, HIV, neuropsychological impairments, cognitive disorders, neuropsychological assessment

\section{Introduction}

Although severe forms of HIV-associated neuropsychological impairments have decreased since the widespread use of combination antiretroviral therapy (cART), such impairments continue to persevere among patients with HIV infection (Heaton et al., 2010; Becker et al., 2011; Grant et al., 2014). Different elements contribute to the development and severity of neuropsychological impairments, such as potentially irreversible brain injury that occurred before patients were started on cART, as well as imperfect blood-brain barrier penetrance leading to inadequate suppression of the adverse effects of HIV on central nervous system (CNS) function [for review, see Heaton et al. (2011)]. In addition, there is a high prevalence of comorbid conditions and confounding factors 
that may interfere with the effects of HIV on the CNS (Weiss et al., 2010), such as CD4 nadir count (Munoz-Moreno et al., 2008; Ellis et al., 2011; Heaton et al., 2011), the time of infection (Ettenhofer et al., 2009), the presence of other infections such as hepatitis $C$ virus, and the use of drugs (Clifford et al., 2005; Shimizu et al., 2011).

Current estimates indicate that as many as $50 \%$ of HIV+ individuals display some degree of neuropsychological impairment (Dawes et al., 2008; Giesbrecht et al., 2014) when impairment is derived from comparisons with normative performance standards (e.g., Heaton et al., 2011; Giesbrecht et al., 2014). Nevertheless, a recent meta-analysis revealed lesser attentional, motor, and executive skill impairments in HIV + individuals treated with cART (Al-Khindi et al., 2011). Although neuropsychological profiles vary among HIV+ individuals (Giesbrecht et al., 2014), deficits in speed of information processing (Llorente et al., 1998; Carey et al., 2004, 2006; Giesbrecht et al., 2014), fine motor speed and dexterity (Chang et al., 2002; Judd et al., 2005), aspects of learning and memory (Peavy et al., 1994; Carey et al., 2006; Martin et al., 2007; Maki et al., 2009), especially verbal memory (Seider et al., 2014) and prospective memory (Doyle et al., 2013), abstraction (Heaton et al., 1995), and attention (Heaton et al., 1995; Hardy and Hinkin, 2002; Levine et al., 2008). Multiple domains of executive functioning, such as cognitive flexibility, decision-making, and planning (Chang et al., 2002; Iudicello et al., 2008; MunozMoreno et al., 2008; Cattie et al., 2012), have also been commonly identified and described.

Despite significant advances in our knowledge over the past 20 years regarding the prevalence, clinical correlates, and functional impact of HIV-associated neuropsychological impairments, we still know very little about the different types of neuropsychological profiles, which are HIV-associated in different populations. A limitation of the existing literature examining cognitive disorders in HIV is the underrepresentation of certain types of infected populations with HIV. Neuropsychological impairments have been mainly studied in HIV-seropositive $(\mathrm{HIV}+)$ patients infected vertically or postnatally during the earliest period of life of the child (e.g., through breast milk) or in specific cohorts of adults such as drug users. Both such macro-categories present confounding factors that may also affect cognitive performance, therefore making it difficult to identify the cognitive impairments attributable to HIV infection. Indeed, it has been shown that children infected vertically or immediately postnatally present adjunctive disorders (Isanaka et al., 2009; Siegfried et al., 2011), such as HIV-related dysfunctions in energy balance (Henderson et al., 1994; Mulligan et al., 1997; Johann-Liang et al., 2000; Batterham, 2005), neuro-developmental growth changes (Rondanelli et al., 2002; Van Rossum et al., 2003), and neurological changes (Reger et al., 2002; Heaton et al., 2004; Antinori et al., 2007). In the cohort of drug users, patients show different neuropsychological impairments; however, these profiles are often difficult to describe because they are complicated by a myriad of confounding factors such as the abuse of substances as alcohol, cocaine, and opiates (Starace et al., 1998; Lundqvist, 2010; Buttner, 2011), emotional disorders, such as anxiety and depression (Byrd et al., 2013), and different risk behaviors (De Ronchi et al., 2002).
While cognitive disorders in HIV are prolific in these areas of research, they remain comparatively understudied in other cohorts of patients, for example, patients who were medically induced with HIV infection through blood transfusions. Such patients represent an interesting cohort because they were generally infected postnatally at an older age, and because they generally do not present the confounding factors of drug-user populations (Rubin et al., 1999; Brown et al., 2000; Ettenhofer et al., 2009). Among these patients, those with hemophilia represent a particularly interesting cohort of patients (Riva et al., 2014a).

\section{Hemophilia}

Hemophilia is a rare coagulation disorder in which a crucial clotting factor in blood is missing either partly or completely. Being a sex chromosome-gene-related bleeding disorder, it occurs primarily in the male population (White et al., 2001). The clinical hallmark of hemophilia is recurrent spontaneous bleeding, most frequently in joints such as the ankles, elbows, and knees, as well as in muscles (Kern et al., 2004; Muça-Perja et al., 2012; Gringeri et al., 2013). The treatment of hemophilia is based on the replacement of the missing clotting factor when bleeding occurs (on-demand treatment) or on a regular and continuous basis (prophylactic treatment) (Santagostino and Mannucci, 2000). In the western world, prophylactic treatment of young hemophiliac patients is considered as current best practice (Krasuska et al., 2012; Santoro et al., 2013; Franchini et al., 2014). Generally, prophylaxis with clotting factors is initiated in childhood after the first joint bleed by the age of 2-4 years (Santagostino and Mannucci, 2000; Makris, 2012; Richards et al., 2012). One of the greatest risks faced by those with hemophilia in the late 1970s and early 1980s was the possibility of contracting HIV, commonly known as the AIDS virus (Franchini and Mannucci, 2012; Mangiafico et al., 2012). This happened when people received transfusions of clotting factors drawn from infected blood. It is estimated that $60-70 \%$ of people with hemophilia were infected with HIV in this way between 1979 and 1985 (Mannucci, 2005). In those years, blood donations were not tested for HIV and people with hemophilia were especially likely to get infected for two reasons: they received many transfusions, and each transfusion contained pooled clotting factors drawn from the blood of numerous donors in order to obtain enough clotting factors to be effective. If any one of those donors happened to be infected with HIV, then the hemophiliac was at risk.

For this reason, the cohort of patients who have both hemophilia and HIV represents a different and interesting cohort of HIV patients to be evaluated in relation to neuropsychological impairments.

However, studies on HIV+ hemophiliacs and neuropsychological impairments are sparse and not very recent. The most important investigation in this field was the Hemophilia Growth and Development Study (HGDS) by Hilgartner et al. (1993). The HGDS was a multicenter study of the long-term effects of HIV infection on growth and neurodevelopment in HIV + hemophiliac children and adolescents most of whom were asymptomatic for HIV disease at baseline, in comparison to a group of HIVhemophiliacs of similar age. Longitudinal and prospective data from the HGDS identified some specific impairments at the 
memory level (Loveland et al., 2000; Nichols et al., 2000), attention (Watkins et al., 2000), and language. These impairments, however, were not clearly described in relation to HIV infection but as neuropsychological impairments related to socio-educational covariates such as school absenteeism and poorer academic achievement, which frequently marked these young patients.

The other few studies have identified cognitive impairment in HIV+ hemophiliacs as related to the decrease in immunological functioning, especially when the CD4+ cell count is lower than 200. For example, Riedel et al. (1992) identified a linear association between neuropsychological impairment in attention, motor skills, visual performance, and the decrease of CD4+. Similarly, Blanchette et al. (2002) identified impairments in motor speed and fine motor skills, and Nichols et al. (2000) concluded that HIV + hemophiliacs presented deficits in communication skills in relation to their immune-functioning system.

Although there are some studies available in the context of a pediatric population, studies are totally underrepresented in the adult population with mixed and confusing results (Turnbull et al., 1991; Riedel et al., 1992). The only two exceptions are the work of Siboni et al. (2009) and Zanon et al. (2014). The first work compared the Mini-Mental State Examination (MMSE) in a hemophiliac HIV - population with the general population, in which differences were not found to be significant. Similarly, the second work determined that HIV- adult hemophiliacs presented a normal overall cognitive performance as measured by the MMSE >25 (Folstein et al., 1975). Alterations occurred only in some patients and they were associated with the presence of spontaneous brain hemorrhage (microbleeds).

However, no prospective studies about adults HIV + hemophiliacs are currently available.

Therefore, understanding the temporal course and the mechanisms of cognitive impairment in this cohort of patients represents an important goal of current research in order to broaden and deepen our current understanding of the impact of HIV on postnatal growth.

Considering the lack of research consensus about the type of neuropsychological impairments and the scarcity of research in the context of hemophilia, the present study aimed to assess the presence and the extent of neuropsychological impairments in a randomly selected cohort of HIV + adult hemophiliacs comparing the performance of this cohort with that of a control group composed of HIV - hemophiliacs.

\section{Materials and Methods}

\section{Participants}

Fifteen HIV+ hemophiliacs (experimental group) and 30 HIVhemophiliacs (control group) were administered neurocognitive batteries between December 2012 and December 2013. Consecutive patients were recruited through their treating physicians via the hemophilia and thrombosis outpatient clinics for three Italian centers. All hemophiliacs had adequate Italian language fluency for the purpose of valid psychometric testing. The inclusion criteria for the experimental group were as follows: diagnosis of hemophilia, diagnosis of HIV with CD4+ counts consistently
TABLE 1 | Participants characteristics.

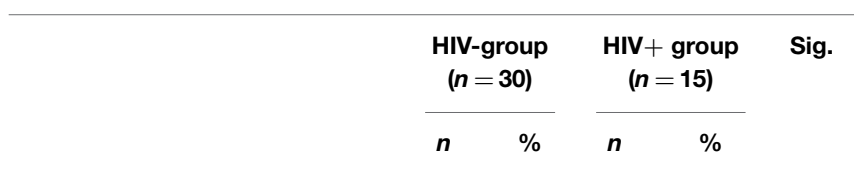

\begin{tabular}{lrrrrr}
\hline Highest educational attainment & & & & & $0.060^{\text {a }}$ \\
Primary school & 3 & 10 & 1 & 7 & \\
Secondary school & 3 & 10 & 8 & 53 & \\
High school & 18 & 60 & 5 & 33 & \\
$\begin{array}{l}\text { University } \\
\text { Currently in professional occupation }\end{array}$ & 6 & 20 & 1 & 7 & $0.255^{\text {b }}$ \\
Yes & 23 & 77 & 9 & 54 & \\
No (unemployed/disability pension) & 7 & 23 & 6 & 46 & \\
\hline & $\mathbf{M}$ & SD & $\mathbf{M}$ & SD & \\
\hline Age & 44 & 8.9 & 45 & 8.4 & $0.446^{\text {a }}$ \\
\hline
\end{tabular}

a Mann-Whitney $U$ test.

${ }^{b}$ Chi-square test.

$>200$ cells $/ \mathrm{mm}^{3}$, treatment with cART, age $>18$ years. Exclusion criteria included diagnosis of AIDS, serious mental illness with a certificated diagnosis (e.g., major depression, anxiety, bipolar disorder), or known CNS pathology, including progressive multifocal leukoencephalopathy, cancer affecting the brain, neurosyphilis, active cytomegalovirus infection, multiple sclerosis, stroke, and seizures/epilepsy. Control patients had a diagnosis of hemophilia and were tested for HIV antibody upon recruitment to the study unless they had a negative test in the past 3 months with no other illness during this time period.

Neurocognitive assessment was conducted by the first author (Silvia Riva) in Milan and Naples and by Silvia Riva and Ilaria Cutica (co-authors) in Rome. Table 1 summarizes the patients enrolled in the three hospitals.

\section{Ethics Statement}

Written informed consent was obtained from each patient. The study was approved by the institutional ethical committees of the three Italian centers involved in this study: the IRCCS Ca'Granda (Milan), The Umberto I Hospital (Milan), and the S. Giovanni Bosco Hospital (Naples) (reference number of IRCCs Ca'Granda, coordinator center: 18092012). The study was conducted in accordance with the Helsinki Declaration (59th WMA General Assembly, Seoul, 2008).

\section{Neuropsychological Assessment}

Patients completed an extensive neuropsychological test battery measuring five major cognitive domains. Attention (1) was assessed by the Trail Making Test (TMT), which is a neuropsychological test of visual attention and task switching (Tombaugh Nichols et al., 2000). Memory (2) was assessed by the Letter-Number Sequencing of the Weschler Adult Intelligence Scale, third edition (WAIS-III) (Wechsler, 1995), which measures the number storage capacity of the working memory (Digit span memory). Language Comprehension (3) was assessed with the short version of the Token Test, which is a valuable measure for assessing receptive language (Spellacy and Spreen, 1969). Visual recognition (4) was assessed by the Rey Tangled Lines Task (Rey, 
1964), a visual tracking and visuomotor processing task. Finally, executive functions (5) were assessed widely by the Clock-drawing Test (Freedman et al., 1994), which is a widespread test used for screening cognitive impairments and dementia and measures spatial dysfunctions and neglect, by the Verbal Fluency test (Lezak, 1995) designed to test phonemic memory in which participants have to say as many words as possible from a category in a given time ( $60 \mathrm{~s}$ ), and by the Italian Test of abstraction of the Brief Neuropsychological Exam (Mondini et al., 2003) aimed at detecting the ability of logical reasoning and generalization of concepts.

\section{Procedure}

After pre-selection of patients, patients were asked to give their written consent to data collection by signing the data protection form. Neuropsychological profiles were based on neuropsychological assessment and recorded by means of documentation forms that were completed by the research psychologist (Silvia Riva). Patient status (HIV+ or HIV-) was blinded to the examiner. The examiner was not blinded only for the data analysis phase.

Overall patient clinical status was evaluated at routine medical appointments, including presence of concomitant diseases and the monitoring of safety variables (e.g., adverse events).

\section{Sample Size Determination}

The optimal sample size was calculated through analyzing and integrating related publications on cross-sectional studies (Riedel et al., 1992; Blanchette et al., 2002) via effect sizes ( $F$-values respective $\eta$-square-values, Cohen's $d$, and $\Lambda$ for multivariate approaches) with $G^{\star}$ Power (Faul et al., 2007). A synopsis of needed sample sizes for the different articles and different outcome measures within the articles was constructed and evaluated. This resulted in an approximate value of the minimum total sample size of 10 cases and 20 controls with a case-control ratio of 1:2. There were two essential reasons for considering the 1:2 matching scheme: (1) concern for sufficient numbers in stratified analysis; (2) increasing power given the expected prevalence (Hennessy et al., 1999). Overall, we enrolled 45 patients: 15 cases and 30 controls.

The sample size calculation took into account the prevalence of hemophilia as a rare disease (10 per 100,000 males born) and the incidence of HIV (currently, around $70 \%$ of diagnosed hemophiliac patients are $\mathrm{HIV}+$ because of receiving infected blood products prior to the availability of HIV screening) (Clinical and Epidemiological Key Elsevier, 2014).

In order to avoid bias in the inclusion phase, we collected a complete list of the patients, and chose patients via the use of a random number generator. HIV - hemophiliacs were matched with HIV patients by age ( \pm 5 years).

\section{Statistical Analysis}

All comparisons made between HIV + and HIV - groups were conducted on raw cognitive data. For conventional neurocognitive measures (Trail Making Test, Digit Span, Verbal Fluency Test), performance of the HIV+ group was further inspected in the context of published normative data using the following procedures. First, each HIV+ participant's raw score was converted to its corresponding age-corrected standard score based upon the published norm-referenced data.

Given the relatively small number of participants, the nonnormality of several distributions and the unbalanced groups, we decided to use the exact methods with Monte-Carlo approximation: a series of non-parametric statistical algorithms that enable researchers to make reliable inferences when data are sparse, heavily tied or unbalanced, not normally distributed, or fail to meet any of the underlying assumptions necessary for reliable results using the standard asymptotic method (Siegel and Castellan, 1988). The exact methods with Monte-Carlo approximation used for comparisons were the Wilcoxon-Mann-Whitney Test for continuous measures, and Chi-square for categorical variables ( $\alpha=0.05$, two-tailed).

Finally, one-way ANCOVAs were conducted to compare the scores between the two groups on raw data of neuropsychological measures that were obtained in both groups, co-varying for age, education, and working status.

\section{Results}

\section{Patients Characteristics}

$\mathrm{HIV}+$ and HIV - hemophiliac patients were matched on age; however, no significant differences were found for other sociodemographic variables, such as education, and working status. It is worth noting the frequency of patients with disability pension or unemployed (higher percentage in the HIV+ group) and the smaller presence of patients with a high level of schooling (particularly in the HIV + group). Details are presented in Table 1.

\section{Neuropsychological Assessment Results}

Scores on the cognitive domains and on each individual test (raw test scores \pm SD for tests) of the two groups are shown in Table 2. Subsequent analyses of the individual domains showed a significantly worse performance of $\mathrm{HIV}+$ hemophiliacs on the domains Attention (Trail Making A test, $U=104.50, z=-2.80$, $p=0.005$; Trail Making B test, $U=107.00, z=-2,73, p=0.006$ ), Memory (Digit Span memory, $U=141.00, z=-2.06, p=0.039$ ), and Abstraction $(U=144.00, z=-2.06, p=0.039)$, and Visual recognition $(U=115,00, z=-2.56, p=0.010)$.

\section{HIV+ Patients' Neuropsychological Impairments Relative to Normative-Referenced Standards}

When the HIV+ hemophilia patients' neuropsychological performances were indexed in accordance with published normativereferenced standards, the magnitude of impairments appeared comparable to data estimated on raw scores in relation to Executive functions (Phonemic memory) $(U=217.00, z=-0.013$, $p=0.990$ ) and to Attention (Trail Making A: $U=110.00$, $z=-2.79, p=0.005$; Trail Making B: $U=150.00, z=-2.10$, $p=0.005)$.

The only exception was for the task of Memory, where the magnitude of impairment was not significant $(U=183.00, z=-1.68$, $p=0.286)$. 
TABLE 2 | Neuropsychological test results on the different cognitive domains and on each test for the HIV - and the HIV+ hemophiliac groups.

\begin{tabular}{|c|c|c|c|c|}
\hline Cognitive domains & $\begin{array}{c}\text { HIV-group } \\
(n=30) \\
\text { Mean (SD) }\end{array}$ & $\begin{array}{c}\text { HIV }+ \text { group } \\
(n=15) \\
\text { Mean (SD) }\end{array}$ & $p$-Value & $\begin{array}{l}r(Z / \\
\sqrt{ } \boldsymbol{N})^{*}\end{array}$ \\
\hline \multicolumn{5}{|l|}{ Attention } \\
\hline Trail Making Test A & $40.38( \pm 12.91)$ & $60.93( \pm 24.52)$ & 0.005 & 0.45 \\
\hline Trail Making Test B & $128.66( \pm 57.38)$ & $173.53( \pm 63.39)$ & 0.002 & 0.47 \\
\hline \multicolumn{5}{|l|}{ Memory } \\
\hline Digit span memory & $4.90( \pm 1.34)$ & $3.93( \pm 1.71)$ & 0.039 & 0.34 \\
\hline Phonemic memory & $31.45( \pm 6.13)$ & $27.53( \pm 6.20)$ & 0.619 & 0.01 \\
\hline \multicolumn{5}{|l|}{ Abstraction } \\
\hline Test of abstraction & $5.13( \pm 1.19)$ & $4.40( \pm 1.29)$ & 0.39 & 0.34 \\
\hline \multicolumn{5}{|l|}{ Language } \\
\hline Token Test & $4.97( \pm 0.18)$ & $4.73( \pm 0.79)$ & 0.131 & 0.03 \\
\hline \multicolumn{5}{|l|}{ Visual recognition } \\
\hline Rey Tangled Lines Task & $3.54( \pm 0.83)$ & $2.67( \pm 1.17)$ & 0.008 & 0.39 \\
\hline \multicolumn{5}{|l|}{ Executive function } \\
\hline Clock-drawing Test & $7.27( \pm 1.80)$ & $6.77( \pm 1.20)$ & 0.340 & 0.02 \\
\hline
\end{tabular}

Test scores are presented as mean raw test scores $\pm S D$.

Mann-Whitney $U$ test with Monte-Carlo $p$ estimation between groups.

${ }^{*} r=$ effect size. Small size $=0.1$; medium size $=0.3$; large size $=0.5$.

\section{ANCOVA and Interactions}

In addition to analyzing overall neuropsychological impairment, we were interested to determine whether any specific areas of neuropsychological performance were impacted by the interaction of age, educational level, and working status. This was accomplished by ANCOVA, controlling for the effect of age, education, and working status.

The analysis controlled for age and education and working status revealed that the $\mathrm{HIV}+$ hemophiliac group performed worse than the HIV - hemophiliac group on Attention with regard to the Trail Making A Test $(F=12.379, p=0.001)$, on Executive Functions with the test of Abstraction $(F=5.274, p=0.027)$ and Visual recognition $(F=5.583, p=0.022)$.

However, the predicted main effect of age was not significant $\left(F=2.00, p=0.16, \eta_{\mathrm{p}}^{2}=0.003\right)$, neither was the predicted main effect of education $\left(F=3.25, p=0.072, \eta_{\mathrm{p}}^{2}=0.004\right)$, and nor was the predicted main effect of working status $(F=3.33, p=0.081$, $\left.\eta_{\mathrm{p}}^{2}=0.008\right)$. The interaction among age, education, and working status was also not significant $\left(F=0.016, p=0.90, \eta_{\mathrm{p}}^{2}=0.001\right)$.

Although the introduction of covariates reduced the distance between the two groups of hemophiliacs (HIV + and HIV-), they did not eliminate the effect of HIV infection on neuropsychological impairment completely. Therefore, the presence of these covariates (age, educational level, and working status), even though they did have an impact, did not explain group differences perse.

\section{Discussion}

Although neuropsychological impairments are well-described in some specific HIV populations, very few studies have investigated the cohort of patients with hemophilia and HIV. In addition, they have often yielded inconsistent results, mainly due to methodological differences. Furthermore, only a few such studies were performed in the cART era.
Moreover, as most of them were conducted on pediatric populations and not on adults, the generalizability of their findings is highly impaired. All these factors limit the generalizability of findings across this relatively small body of work.

By contrast, our current pilot study carefully defined and investigated cognitive disorders using standardized clinical tasks in a defined, well-characterized cohort of patients with HIV. This pilot examination revealed that in a small but well-controlled sample, it was possible to detect some signals of neuropsychological impairment in the context of hemophilia patients with HIV. More specifically, the results of this study showed a worse performance on neuropsychological assessment in our sample of $\mathrm{HIV}+$ hemophiliacs compared with the control group of HIVhemophiliacs, when combining all tests in one overall analysis.

The HIV + hemophiliacs had significantly lower scores on tests of attention, memory, executive function (abstraction test), and visual recognition than did the control group. However, when adjusted for age, education, and working status, the real distance between the two groups reduced, and the difference on memory revealed to be not significant. The observation of an HIV effect on tests requiring rapid processing of information (attention) is consistent with the classic conceptualization of HIV as a subcortical disease targeting frontal-striatal circuits supporting these abilities (Reger et al., 2002; Baldewicz et al., 2004).

The finding of a decline in abstraction function is unique in the cohort of HIV+ hemophilia patients even though it has been observed in the general HIV population (Heaton et al., 1995).

Impairments in language were not found in our study. The absence of language disorders appears to contrast slightly with the main research on cognitive disorders in hemophilia, namely that conducted in the HGDS. Indeed, in the HGDS, the authors found the presence of language disorder in $\mathrm{HIV}+$ pediatric patients but concluded that this disorder was associated with socio-educational factors, since these patients were more exposed to school absenteeism and lower school participation due to the management of their physical conditions requiring frequent medical examinations. However, our results cannot be completely compared with those of the HGDS as our sample was composed of adult patients and not of children or adolescents.

Regarding the ANCOVA analysis, we found a correlation between cognitive disorders and socio-demographic factors (age, education, and working status) as reported in the HIV literature. Even this result is innovative in the field of hemophilia and $\mathrm{HIV}$ in the adult population, especially regarding working status. However, these differences cannot be totally attributable to these covariates and it is reasonable to attribute a weight to the HIV infection.

Future comprehensive studies, however, are expected to explore the above-mentioned relationship and to clarify more concisely the weight of each confounding factor, not only cross-sectionally but also longitudinally.

Taken together, these findings, while preliminary, highlight important considerations for the design of clinical research studies exploring the cognitive effects of HIV in hemophiliacs. The current study adds to the growing literature on HIV+ hemophiliacs and cognition in the cART era and was strengthened by selective inclusion criteria (such as the level of CD4 $>200$, the absence of a 
psychiatric disorder, such as a diagnosis of depression/anxiety), thereby allowing the evaluation of a precise and representative cohort. Previous studies either lacked a matched control group or examined cognition in isolation. One of the main strengths of the current study is that it is one of the few to examine cognitive impairments in the cohort of hemophilia patients in adulthood and provides an update to reference studies, which are not very recent in this field. Also, studies in European samples of HIV patients are very scarce. This study represents one of the firsts European cohort study in hemophilia with HIV patients exploring the level of cognitive impairments.

Another strength is that this study provides an overview of the social situation of these patients who live with another chronic condition, hardly ever reported in the literature. Patients with HIV + hemophilia present a higher rate of unemployment status, and a lower level of schooling, which probably leads to more difficulties in finding a job (Chernoff et al., 2010). Rates of unemployment in HIV + hemophiliacs in this study were comparable to those in chronic illnesses with a recognized disability such as rheumatoid arthritis (Wallenius et al., 2009) but lower than those in other disabling conditions such as multiple sclerosis (Khan et al., 2009). This scenario must also be considered seriously from a social and health policy perspective. A multidisciplinary approach is likely to be needed, addressing both physical and psychological barriers to working, including overcoming perceived barriers to work, increasing confidence and motivation to work, and facilitating skills training and work placement (Kielhofner et al., 2004). The potential for the doctor-patient relationship (Riva et al., 2012; Riva et al., 2014b) in HIV to help promote a return to employment should be considered, with discussion forming a part of the routine HIV consultation.

As with all research, several limitations should be noted. The current study was not designed to longitudinally track the effects HIV on cognitive functioning. Future longitudinal studies may investigate more, in-depth, the presence of cognitive impairment in this population and the relationship with antiretroviral medications in order to evaluate whether and how the value of longterm treatment versus short-term treatment impacts differently on cognitive impairment. Moreover, this study was not additionally designed to compare HIV - hemophiliacs with a parallel sample of the Italian general population because, as shown by the existing literature, the cohort of HIV - hemophiliacs seems not to show any evident cognitive decline compared with the normal population (Siboni et al., 2009). However, a comparison with a specific subgroup from the general population would have further enhanced the study.

This study is limited by its design as a pilot and suffers from methodological challenges, such as the potential instability of the data related to the small sample size. However, the presence of statistically significant results renders the findings even more provocative. Future studies, with larger samples, should be completed to replicate these findings and to test for potential interaction effects among variables of interest. Another limitation is the

\section{References}

Al-Khindi, T., Zakzanis, K. K., and van Gorp, W. G. (2011). Does antiretroviral therapy improve HIV-associated cognitive impairment? A quantitative lack of data on MRI abnormalities and other neurological indicators, which made it impossible to link the neuropsychological assessment results with some neurobiological correlates or other medical observations.

In conclusion, this cross-sectional pilot study showed decrements in the neuropsychological profile, specifically in attention, memory, executive function (abstraction test), and visual recognition in a small, but representative, randomly selected sample of hemophilia patients with HIV+ in comparison with the control group of HIV - hemophilia patients. The findings of the current study indicate that future research should focus on further unraveling the underlying mechanism of neuropsychological impairments, using neuropsychological tests, in combination with neuroimaging techniques in a larger sample.

Finally, the neuropsychological impairments detected in this study have important implications for day-to-day functioning. The level of impairment detected may cause some problems in completing common everyday tasks such as maintaining adherence to complex medication regimens (both for hemophilia and HIV), as well as holding down a full-time job. These impairments, in combination with hemophilia, may make some activities of self-care more cumbersome. As recently pointed out by the work of Fazeli et al. (2014) on HIV patients with associated neurocognitive disorders, working and active engagement in life tend to strengthen neurocognitive functioning, "by enhancing cognitive and/or brain reserve" (p. 234). Continued research into the mechanisms related to HIV and neurocognitive dysfunction may provide targets for interventions that could have meaningful consequences in the real world.

\section{Author Contributions}

RS, as first author, developed the design of the study, carried out the study, performed the statistical analysis, and wrote the manuscript. IC participated in carrying out the study and drafted the manuscript. CK and LR participated in statistical analyses and drafted the manuscript. RESW revised linguistically our paper. CS participated in carrying out the study in Rome. AR participated in carrying out the study in Naples. VR participated in carrying out the study in Milan. GP helped the first author in developing the study and participated in writing of the paper. All authors read and approved the final manuscript.

\section{Acknowledgments}

The first author acknowledges support from Novo Nordisk grant "Changing possibilities in Hemophilia" for the opportunity of conducting this study and the AICE (Italian Association of Hemophilia Centres) for conducting the study in three hemophilia centers in Italy and, particularly, Prof. Mannuccio Mannucci for his support. All the authors thank all the participating patients for their contribution to the study.

review of the literature. J. Int. Neuropsychol. Soc. 17, 956-969. doi:10.1017/ S1355617711000968

Antinori, A., Arendt, G., Becker, J. T., Brew, B. J., Byrd, D. A., Cherner, M., et al. (2007). Updated research nosology for HIV-associated neurocognitive 
disorders. Neurology 69, 1789-1799. doi:10.1212/01.WNL.0000287431.88 $658.8 \mathrm{~b}$

Baldewicz, T. T., Leserman, J., Silva, S. G., Petitto, J., Golden, R. N., Perkins, D. O., et al. (2004). Changes in neuropsychological functioning with progression of HIV-1 infection: results of an 8-year longitudinal investigation. AIDS Behav. 8, 345-355. doi:10.1023/B:AIBE.0000044081.42034.54

Batterham, M. J. (2005). Investigating heterogeneity in studies of resting energy expenditure in persons with HIV/AIDS: a meta-analysis. Am. J. Clin. Nutr. 81, $702-713$.

Becker, B. W., Thames, A. D., Woo, E., Castellon, S. A., and Hinkin, C. H. (2011). Longitudinal change in cognitive function and medication adherence in HIV-infected adults. AIDS Behav. 15, 1888-1894. doi:10.1007/ s10461-011-9924-z

Blanchette, N., Smith, M. L., King, S., Fernandes-Penney, A., and Read, S. (2002). Cognitive development in school-age children with vertically transmitted HIV infection. Dev. Neuropsychol. 21, 223-241. doi:10.1207/S15326942DN2103_1

Brown, L. K., Lourie, K. J., and Pao, M. (2000). Children and adolescents living with HIV and AIDS: a review. J. Child Psychol. Psychiatry 41, 81-96. doi:10.1017/ S0021963099004977

Buttner, A. (2011). Review: the neuropathology of drug abuse. Neuropathol. Appl. Neurobiol. 37, 118-134. doi:10.1111/j.1365-2990.2010.01131.x

Byrd, D. A., Robinson-Papp, J., Rivera Mindt, R., Mintz, L., Elliott, K., Lighty, Q., et al. (2013). Isolating cognitive and neurologic HIV effects in substancedependent, confounded cohorts: a pilot study. J. Int. Neuropsychol. Soc. 19, 463-473. doi:10.1017/S1355617712001634

Carey, C. L., Woods, S. L., Rippeth, J. D., Heaton, R. K., Grant, I., and The HIV Neurobehavioral Research Center (HNRC) Group. (2006). Prospective memory in HIV-1 infection. J. Clin. Exp. Neuropsychol. 28, 536-548. doi:10.1080/ 13803390590949494

Carey, C. L., Woods, S. P., Rippeth, J. D., Gonzalez, R., Moore, D. J., Marcotte, T. D., et al. (2004). Initial validation of a screening battery for the detection of HIVassociated cognitive impairment. Clin. Neuropsychol. 18, 234-248. doi:10.1080/ 13854040490501448

Cattie, J. E., Doyle, K., Weber, E., Grant, I., Woods, S. P., and The HIV Neurobehavioral Research Program (HNRP) Group. (2012). Planning deficits in HIV-associated neurocognitive disorders: component processes, cognitive correlates, and implications for everyday functioning. J. Clin. Exp. Neuropsychol. 34, 906-918. doi:10.1080/13803395.2012.692772

Chang, L., Ernst, T., Witt, M. D., Ames, N., Gaiefsky, M., and Miller, E. (2002). Relationships among brain metabolites, cognitive function, and viral loads in antiretroviral naive HIV patients. Neuroimage 17, 1638-1648. doi:10.1006/nimg. 2002.1254

Chernoff, R. A., Martin, D. J., Schrock, D. A., and Huy, M. P. (2010). Neuropsychological functioning as a predictor of employment activity in a longitudinal study of HIV-infected adults contemplating workforce reentry. J. Int. Neuropsychol. Soc. 16, 38-48. doi:10.1017/S1355617709990828

Clifford, D. B., Evans, S. R., Yang, Y. J., and Gulick, R. M. (2005). The neuropsychological and neurological impact of hepatitis $\mathrm{C}$ virus co-infection in HIV-infected subjects. AIDS 19, S64-S71. doi:10.1097/01.aids.0000192072.80572.43

Clinical and Epidemiological Key Elsevier. (2014). Available at: https://www. clinicalkey.com/topics/hematology/hemophilia.html

Dawes, S., Suarez, P., Casey, C. Y., Cherner, M., Marcotte, T. D., Letendre, S., et al. (2008). Variable patterns of neuropsychological performance in HIV-1 infection. J. Clin. Exp. Neuropsychol. 30, 613-626. doi:10.1080/13803390701565225

De Ronchi, D., Faranca, I., Berardi, D., Scudellari, P., Borderi, M., Manfredi, R., et al. (2002). Risk factors for cognitive impairment in HIV-1-infected persons with different risk behaviours. Arch. Neurol. 59, 812-818. doi:10.1001/archneur. 59.5.812

Doyle, K. L., Loft, S., Morgan, E. E., Weber, E., Cushman, C., Johnston, E., et al. (2013). Prospective memory in HIV-associated neurocognitive disorders (HAND): the neuropsychological dynamics of time monitoring. J. Clin. Exp. Neuropsychol. 35, 359-372. doi:10.1080/13803395.2013.776010

Ellis, R. J., Badiee, J., Vaida, F., Letendre, S., Heaton, R. K., Clifford, D., et al. (2011). CD4 nadir is a predictor of HIV neurocognitive impairment in the era of combination antiretroviral therapy. AIDS 25, 1747-1751. doi:10.1097/QAD. 0b013e32834a $40 \mathrm{~cd}$

Ettenhofer, M. L., Hinkin, C. H., Castellon, S. A., Durvasula, R., Ullman, J., Lam, M., et al. (2009). Aging, neurocognition, and medication adherence in HIV infection. Am. J. Geriatr. Psychiatry 17, 281-290. doi:10.1097/JGP. 0b013e31819431bd
Faul, F., Erdfelder, E., Lang, A.-G., and Buchner, A. (2007). G*Power 3: a flexible statistical power analysis program for the social, behavioral, and biomedical sciences. Behav. Res. Methods 39, 175-191. doi:10.3758/BF03193146

Fazeli, P. L., Woods, S. P., Heaton, R. K., Umlauf, A., Gouaux, B., Rosario, D., et al. (2014). An active lifestyle is associated with better neurocognitive functioning in adults living with HIV infection. J. Neurovirol. 20, 233-242. doi:10.1007/ s13365-014-0240-z

Folstein, M. F., Folstein, S. E., and McHugh, P. R. (1975). "Mini-mental state". A practical method for grading the cognitive state of patients for the clinician. $J$. Psychiatr. Res. 12, 189-198.

Franchini, M., Coppola, A., Rocino, A., Zanon, E., Morfini, M., and The Italian Association of Haemophilia Centers (AICE) Working Group. (2014). Perceived challenges and attitudes to regimen and product selection from Italian haemophilia treaters: the 2013 AICE survey. Haemophilia 20, 128-135. doi:10. 1111/hae.12334

Franchini, M., and Mannucci, P. M. (2012). Past, present and future of hemophilia: a narrative review. Orphanet J. Rare Dis. 2, 24.

Freedman, M. I., Leach, L., Kaplan, E., Winocur, G., Shulman, K. J., and Delis, D. C. (1994). Clock Drawing. Oxford: Oxford University Press.

Giesbrecht, C. J., Thornton, A. E., Hall-Patch, C., Maan, E. J., Cote, H. C. F., Money, D. M., et al. (2014). Select neurocognitive impairment in HIV-infected women: associations with HIV viral load, hepatitis $\mathrm{C}$ virus, and depression, but not leukocyte telomere length. PLoS ONE 9:e89556. doi:10.1371/journal.pone. 0089556

Grant, I., Franklin, D. R. Jr., Deutsch, R., Woods, S. P., Vaida, F., Ellis, R. J., et al. (2014). Asymptomatic HIV-associated neurocognitive impairment increases risk for symptomatic decline. Neurology 82, 2055-2062. doi:10.1212/WNL. 0000000000000492

Gringeri, A., Lessinger, C., Berntorp, E., Riva, S., Cortesi, P.A., Fusco, F., et al. (2013). Health- related quality of life in patients with haemophilia and inhibitors on prophylaxis with anti-inhibitor complex concentrate: results from the ProFEIBA study. Haemophilia 19, 736-743. doi:10.1111/hae.12178

Hardy, D. J., and Hinkin, C. H. (2002). Reaction time performance in adults with HIV/AIDS. J. Clin. Exp. Neuropsychol. 24, 912-929. doi:10.1076/jcen.24.7.912. 8391

Heaton, R. K., Clifford, D. B., Franklin, D. R. Jr., Woods, S. P., Ake, C., Vaida, F., et al. (2010). HIV associated neurocognitive disorders persist in the era of potent antiretroviral therapy: CHARTER Study. Neurology 75, 2087-2096. doi:10.1212/WNL.0b013e318200d727

Heaton, R. K., Franklin, D. R., Ellis, R. J., McCutchan, J. A., Letendre, S. L., LeBlanc, S., et al. (2011). HIV-associated neurocognitive disorders before and during the era of combination antiretroviral therapy: differences in rates, nature, and predictors. J. Neurovirol. 17, 3-16. doi:10.1007/s13365-010-0006-1

Heaton, R. K., Grant, I., Butters, N., White, D. A., Kirson, D., Atkinson, J. H., et al. (1995). The HNRC 500: neuropsychology of HIV infection at different disease stages. J. Int. Neuropsychol. Soc. 1, 231-251. doi:10.1017/S1355617700000230

Heaton, R. K., Marcotte, T. D., Mindt, M. R., Sadek, J., Moore, D. J., Bentley, H., et al. (2004). The impact of HIV-associated neuropsychological impairment on everyday functioning. J. Int. Neuropsychol. Soc. 10, 317-331. doi:10.1017 S1355617704102130

Henderson, R. A., Saavedra, J. M., Perman, J. A., Hutton, N., Livingston, R. A., and Yolken, R. H. (1994). Effect of enteral tube feeding on growth of children with symptomatic human immunodeficiency virus infection. J. Pediatr. Gastroenterol. Nutr. 18, 429-434. doi:10.1097/ 00005176-199405000-00004

Hennessy, S., Bilker, W. B., Berlin, J. A., and Stromuet, B. L. (1999). Factors influencing the optimal control-to-case ratio in matched casecontrol studies. Am. J. Epidemiol. 149, 195-197. doi:10.1093/oxfordjournals.aje. a009786

Hilgartner, M. W., Donfield, S. M., Willoughby, A., Contant, C., Evatt, B., Gomperts, E., et al. (1993). Haemophilia Growth and Development Study: design, methods, and entry data. J. Pediatr. Hematol. Oncol. 15, 208-218. doi:10.1097/ 00043426-199305000-00009

Isanaka, S., Duggan, C., and Fawzi, W. W. (2009). Patterns of postnatal growth in HIV-infected and HIV-exposed children. Nutr. Rev. 67, 343-359. doi:10.1111/j. 1753-4887.2009.00207.x

Iudicello, J. E., Woods, S. P., Weber, E., Dawson, M. S., Scott, J. C., and The HIV Neurobehavioral Research Center (HNRC) Group. (2008). Cognitive mechanisms of switching in HIV-associated category fluency deficits. J. Clin. Exp. Neuropsychol. 30, 797-804. doi:10.1080/13803390701779578 
Johann-Liang, R., O’Neill, L., Cervia, J., Licholai, T., and Noel, G. J. (2000). Energy balance, viral burden, insulin-like growth factor-1, interleukin- 6 and growth impairment in children infected with human immunodeficiency virus. AIDS 14, 683-690. doi:10.1097/00002030-200004140-00007

Judd, F., Komiti, A., Chua, P., Mijch, A., Hoy, J., Grech, P., et al. (2005). Nature of depression in patients with HIV/AIDS. Aust. N. Z. J. Psychiatry 39, 826-832. doi:10.1080/j.1440-1614.2005.01659.x

Kern, M., Blanchette, V., Stain, A. M., Einarson, T. R., and Feldman, B. M. (2004). Clinical and cost implications of target joints in Canadian boys with severe hemophilia. J. Pediatr. 145, 628-634. doi:10.1016/j.jpeds.2004.06.082

Khan, F., Ng, L., and Turner-Stokes, L. (2009). Effectiveness of vocational rehabilitation intervention on the return to work and employment of persons with multiple sclerosis. Cochrane Database Syst. Rev. 1:CD007256. doi:10.1002/14651858. CD007256.pub2

Kielhofner, G., Braveman, B., Finlayson, M., Paul-Ward, A., Goldbaum, L., and Goldstein, K. (2004). Outcomes of a vocational program for persons with AIDS. Am. J. Occup. Ther. 58, 64-72. doi:10.5014/ajot.58.1.64

Krasuska, M., Riva, S., Fava, L., von Mackensen, S., and Bullinger, M. (2012). Linking quality-of-life measures using the international classification of functioning, disability and health and the international classification of functioning, disability and health-children and youth version in chronic health conditions: the example of young people with hemophilia. Am. J. Phys. Med. Rehabil. 91, S74-S83. doi:10.1097/PHM.0b013e31823d4f35

Levine, A. J., Hardy, D. J., Barclay, T. R., Reinhard, M. J., Cole, M. M., and Hinkin, C. H. (2008). Elements of attention in HIV-infected adults: evaluation of an existing model. J. Clin. Exp. Neuropsychol. 30, 53-62. doi:10.1080/13803390601186684

Lezak, M. D. (1995). Neuropsychological Assessment. Oxford: Oxford University Press.

Llorente, A. M., Miller, E. N., D’Elia, L. F., Selnes, O. A., Wesch, J., Becker, J. T., et al. (1998). Slowed information processing in HIV-1 disease. The Multicenter AIDS Cohort Study (MACS). J. Clin. Exp. Neuropsychol. 20, 60-72. doi:10.1076/ jcen.20.1.60.1489

Loveland, K. A., Stehbens, J. A., Mahoney, E. M., Sirois, P. A., Nichols, S., Bordeaux, J. D., et al. (2000). Declining immune function in children and adolescents with Haemophilia and HIV infection: effects on neuropsychological performance. J. Pediatr. Psychol. 25, 309-322. doi:10.1093/jpepsy/25.5.309

Lundqvist, T. (2010). Imaging cognitive deficits in drug abuse. Curr. Top. Behav. Neurosci. 3, 247-275. doi:10.1007/7854_2009_26

Maki, P. M., Cohen, M. H., Weber, K., Little, D. M., Fornelli, D., Rubin, L. H., et al. (2009). Impairments in memory and hippocampal function in HIVpositive vs. HIV negative women. Neurology 72, 1661-1668. doi:10.1212/WNL. 0b013e3181a55f65

Makris, M. (2012). Prophylaxis in haemophilia should be life-long. Blood Transfus. 10, 165-168. doi:10.2450/2012.0147-11

Mangiafico, L., Perja, M., Fusco, F., Riva, S., Mago, D., and Gringeri, A. (2012). Safety and effectiveness of raltegravir in patients with haemophilia and anti- HIV multidrug resistance. Haemophilia 18, 108-111. doi:10.1111/j.1365-2516.2011. 02610.x

Mannucci, P. M. (2005). Hemophilia: treatment options on the twenty-first century. J. Thromb. Haemost. 1, 1349-1355. doi:10.1046/j.1538-7836.2003.00262.x

Martin, E. M., Nixon, H., Pitrak, D. L., Weddington, W., Rains, N. A., Nunnally, G., et al. (2007). Characteristics of prospective memory deficits in HIVseropositive substance dependent individuals: preliminary observation. J. Clin. Exp. Neuropsychol. 29, 496-504. doi:10.1080/13803390600800970

Mondini, S., Mapelli, D., Vestri, A., Arcara, G., and Bisiacchi, P. S. (2003). Esame Neuropsicologico Breve. Torino: Cortina Raffaello.

Muça-Perja, M., Riva, S., Grochowska, B., Mangiafico, L., Mago, D., and Gringeri, A. (2012). Ultrasonography of haemophilic arthropathy. Haemophilia 18, 364-368. doi:10.1111/j.1365-2516.2011.02672.x

Mulligan, K., Tai, V. W., and Schambelan, M. (1997). Energy expenditure in human immunodeficiency virus infection. N. Engl. J. Med. 336, 70-71. doi:10.1056/ NEJM199701023360115

Munoz-Moreno, J. A., Fumaz, C. R., Ferrer, M. J., Prats, A., Negredo, E., Garolera, M., et al. (2008). Nadir CD4 cell count predicts neurocognitive impairment in HIV-infected patients. AIDS Res. Hum. Retroviruses 24, 1301-1307. doi:10.1089/ aid. 2007.0310

Nichols, S., Mahoney, E. M., Sirois, P. A., Bordeaux, J. D., Stehbens, J. A., Loveland, K. A., et al. (2000). HIV-associated changes in adaptive, emotional, and behavioral functioning in children and adolescents with haemophilia: results from the
Haemophilia Growth and Development Study. J. Pediatr. Psychol. 25, 545-556. doi:10.1093/jpepsy/25.8.545

Peavy, G., Jacobs, D., Salmon, D. P., Butters, N., Delis, D. C., Taylor, M., et al. (1994) Verbal memory performance of patients with human-immunodeficiency-virus infection - evidence of subcortical dysfunction. J. Clin. Exp. Neuropsychol. 16, 508-523. doi:10.1080/01688639408402662

Reger, M., Welsh, R., Razani, J., Martin, D. J., and Boone, K. B. (2002). A metaanalysis of the neuropsychological sequelae of HIV infection. J. Int. Neuropsychol. Soc. 8, 410-424. doi:10.1017/S1355617702813212

Rey, A. (1964). L'Examen clinique en psycologie. (The Clinical Exam in Psychology). Paris: Presses Universitaires de France.

Richards, M., Lavigne Lissalde, G., Combescure, C., Batorova, A., Dolan, G., Fischer, K., et al. (2012). Neonatal bleeding in haemophilia: a European cohort study. Br. J. Haematol. 156, 374-382. doi:10.1111/j.1365-2141.2011.08967.x

Riedel, R. R., Helmstaedter, C., Bülau, P., Durwen, H. F., Brackmann, H., Fimmers, R., et al. (1992). Early signs of cognitive deficits among human immunodeficiency virus-positive hemophiliacs. Acta Psychiatr. Scand. 85, 321-326. doi:10. 1111/j.1600-0447.1992.tb01476.x

Riva, S., Monti, M., Iannello, P., and Antonietti, A. (2012). The representation of risk in routine medical experience: what actions for contemporary health policy? PLoS ONE 7:e48297. doi:10.1371/journal.pone.0048297

Riva, S., Cutica, I., and Pravettoni, G. (2014a). Is there evidence for neurocognitive dysfunctions in patients with postnatal HIV infection? A review on the cohort of hemophilia patients. Front. Hum. Neurosci. 8:470. doi:10.3389/fnhum.2014. 00470

Riva, S., Monti, M., Iannello, P., Pravettoni, G., Schulz, P., and Antonietti, A. (2014b). A preliminary mixed-method investigation of trust and hidden signals in medical consultations. PLoS ONE 9:e90941. doi:10.1371/journal.pone. 0090941

Rondanelli, M., Caselli, D., Arico, M., Maccabruni, A., Magnani, B., Bacchella, L., et al. (2002). Insulin-like growth factor I (IGF-I) and IGF-binding protein 3 response to growth hormone is impaired in HIV-infected children. AIDS Res Hum. Retroviruses 18, 331-339. doi:10.1089/088922202753519106

Rubin, S. A., Bautista, J. R., Moran, T. H., Schwartz, G. J., and Carbone, K. M. (1999). Viral teratogenesis: brain developmental damage associated with maturation state at time of infection. Brain Res. Dev. Brain Res. 112, 237-244. doi:10.1016/ S0165-3806(98)00180-1

Santagostino, E., and Mannucci, P. M. (2000). Guidelines for replacement treatment of haemophilia and inherited coagulation disorders in Italy. Haemophilia 6, 1-10. doi:10.1046/j.1365-2516.2000.00361.x

Santoro, C., Baldacci, E., Mercanti, C., and Mazzucconi, M. G. (2013). Tailored versus standard dose prophylaxis in children with hemophilia A. Semin. Thromb. Hemost. 39, 711-722. doi:10.1055/s-0033-1354419

Seider, T. R., Assawin Gongvatana, X. L., Devlin, K. N., de la Monte, S. M., Chasman, J. D., Yan, P., et al. (2014). Verbal memory declines more rapidly with age in HIV infected versus uninfected adults. J. Clin. Exp. Neuropsychol. 36, 356-367. doi:10.1080/13803395.2014.892061

Shimizu, S. M., Chow, D. C., Valcour, V., Masaki, K., Nakamoto, B., Kallianpur, K. J., et al. (2011). The impact of depressive symptoms on neuropsychological performance tests in HIV-infected individuals: a study of the Hawaii aging with HIV cohort. World J. AIDS 1, 139-145. doi:10.4236/wja.2011.14020

Siboni, S. M., Mannucci, P. M., Gringeri, A., Franchini, M., Tagliaferri, A., Ferretti, M., et al. (2009). Health status and quality of life of elderly persons with severe hemophilia born before the advent of modern replacement therapy. J. Thromb. Haemost. 7, 780-786. doi:10.1111/j.1538-7836.2009.03318.x

Siegel, S., and Castellan, J. Jr. (1988). Nonparametric Statistics for the Behavioral Sciences. New York, NY: McGraw-Hill.

Siegfried, N., van der Merwe, L., Brocklehurst, P., and Sint, T. T. (2011). Antiretrovirals for reducing the risk of mother-to-child transmission of HIV infection. Cochrane Database Syst. Rev. 6, CD003510. doi:10.1002/14651858.CD003510. pub3

Spellacy, F. J., and Spreen, O. (1969). A short form of the token test. Cortex 5, 390-397. doi:10.1016/S0010-9452(69)80015-8

Starace, F., Baldassarre, C., Biancolilli, V., Fea, M., Serpelloni, G., Bartoli, L., et al. (1998). Early neuropsychological impairment in HIV-seropositive intravenous drug users: evidence from the Italian Multicentre Neuropsychological HIV Study. Acta Psychiatr. Scand. 97, 132-138. doi:10.1111/j.1600-0447.1998. tb09975.x 
Tombaugh Nichols, S., Mahoney, E. M., Sirois, P. A., Bordeaux, J. D., Stehbens, J. A., Loveland, K. A., et al. (2000). HIV-associated changes in adaptive, emotional, and behavioral functioning in children and adolescents with haemophilia: results from the Haemophilia Growth and Development Study. J. Pediatr. Psychol. 25, 545-556. doi:10.1093/jpepsy/25.8.545

Turnbull, O., Saling, M. M., Kaplan-Solms, K., Cohn, R., and Schoub, B. (1991). Neuropsychological deficit in haemophiliacs with human immunodeficiency virus. J. Neurol. Neurosurg. Psychiatry 54, 175-177.

Van Rossum, A. M., Gaakeer, M. I., Verweel, S., Hartwig, N. G., Wolfs, T. F., Geelen, S. P., et al. (2003). Endocrinologic and immunologic factors associated with recovery of growth in children with human immunodeficiency virus type 1 infection treated with protease inhibitors. Pediatr. Infect. Dis. J. 22, 70-76. doi:10.1097/00006454-200301000-00017

Wallenius, M., Skomsvoll, J. F., Koldingsnes, W., Kaufmann, C., and Kvien, T. K. (2009). Comparison of work disability and health-related quality of life between males and females with rheumatoid arthritis below the age of 45 years. Scand. J. Rheumatol. 2009, 178-183. doi:10.1080/03009740802400594

Watkins, J. M., Cool, V. A., Usner, D., Stehbens, J. A., Nichols, S., Loveland, K. A., et al. (2000). Attention in HIV-infected children: results from the Hemophilia Growth and Development Study. J. Int. Neuropsychol. Soc. 6, 443-454. doi:10. 1080/13548500903012897

Wechsler, S. (1995). The Semantic Basis of Argument Structure. New York, NY: CSLI Publications (Center for the Study of Language and Information). Stanford, Cambridge University Press.
Weiss, J. J., Osorio, G., Ryan, E., Marcus, S. M., and Fishbein, D. A. (2010). Prevalence and patient awareness of medical comorbidities in an urban AIDS clinic. AIDS Patient Care STDS. 24, 39-48. doi:10.1089/apc.2009.0152

White, G. C., Rosendaal, F., Aledort, L. M., Lusher, J. M., Rothschild, C., Ingerslev, J., et al. (2001). Definitions in hemophilia. Recommendation of the scientific subcommittee on factor VIII and factor IX of the scientific and standardization committee of the International Society on Thrombosis and Haemostasis. Thromb. Haemost. 85, 560.

Zanon, E., Manara, R., Milan, M., Brandolin, B., Mapelli, D., Mardari, R., et al. (2014). Cognitive dysfunctions and cerebral microbleeds in adult patients with haemophilia A: a clinical and MRI pilot-study. Thromb. Res. 134, 851-855.

Conflict of Interest Statement: The authors declare that the research was conducted in the absence of any commercial or financial relationships that could be construed as a potential conflict of interest.

Copyright (๑ 2015 Riva, Cutica, Krampe, Reinecke, Russell-Edu, Santoro, Rocino, Santagostino, Rusconi and Pravettoni. This is an open-access article distributed under the terms of the Creative Commons Attribution License (CC BY). The use, distribution or reproduction in other forums is permitted, provided the original author(s) or licensor are credited and that the original publication in this journal is cited, in accordance with accepted academic practice. No use, distribution or reproduction is permitted which does not comply with these terms. 